\title{
PENGELOLAAN PENDIDIKAN AGAMA ISLAM DI ISLAMIC FULL DAY SCHOOL SMP SALMAN AL-FARISI BANDUNG
}

\author{
Andri Ramdani Sumarna,* Abas Asyafah, dan Aceng Kosasih \\ Universitas Pendidikan Indonesia \\ *E-mail: aramdanisumarna@gmail.com
}

\begin{abstract}
The purpose of this study is to know the management of Islamic religious education in full day school Islamic Junior High School Salman Al-Farisi Bandung starting from planning, implementation, and results and advantages and weaknesses of PAI in full-day school program. The research conducted using qualitative approach descriptive method. To obtain research data, researchers used the method of observation, interview, and documentation. The results showed that: (1) Planning of Islamic education expanded into subjects tilawwati, tahfi $\dot{2}$, matrikulasi, and hours wali kelas for the seven sunnah habituation. Basic competencies are mapped into aspects of leadership and green education. (2) The implementation of Islamic education is carried out by teachers of PAI, other teacher and special teachers integrated in leadership, green education and IMTAQ (3) The result of Islamic education is evidenced by the special report of the application of Islamic education (4) with educational background become weakness of SAF Islamic Junior High School full day. The integration of the concept of leadership, green education in PAI as well as the habituation of seven sunnab became the excellence of SMP SAF Islamic full day school to achieve khalifatullàh fi al-Ardi the rahmatan lil'alamin ".
\end{abstract}

Keywords: Management, Islamic Education, Islamic Full Day School.

\begin{abstract}
ABSTRAK
Tujuan penelitian ini adalah untuk mengetahui pengelolaan pendidikan agama Islam di Islamic full day school SMP Salman Al-Farisi Bandung. Penelitian yang dilakukan menggunakan pendekatan kualitatif dan metode deskriptif. Untuk memperoleh data penelitian, peneliti menggunakan metode observasi, wawancara, dan dokumentasi. Hasil penelitian menunjukkan babwa: (1) Perencanaan pendidikan agama Islam diperluas ke dalam mata pelajaran tilawati, tahfi walikelas untuk pembiasaan seven sunnah. Kompetensi dasar dipetakan ke dalam aspek leadership dan green education. (2) Pelaksanaan pendidikan agama Islam dilaksanakan oleh guru PAI, guru mapel lain dan guru khusus yang terintegrasi dalam leadership, green education dan IMTAQ (3) Hasil pendidikan agama Islam dibuktikan dengan laporan kbusus aplikasi pendidikan agama Islam (4) Guru PAI yang tidak sesuai dengan latar belakang pendidikan menjadi kelemahan SMP $S A F$ Islamic full day school. Pengintegrasian konsep leadership, green education dalam PAI serta pembiasaan seven sunnah menjadi keunggulan SMP SAF Islamic full day school untuk mencapai khalifatulläh fil Arḍ i yang rahmatan lil'älamin".
\end{abstract}

Kata Kunci: Islamic Full Day School, Pendidikan Agama Islam, Pengelolaan. 


\section{PENDAHULUAN}

Memasuki era globalisasi, berbagai permasalahan pendidikan semakin banyak bermunculan dan berkembang seperti rendahnya kualitas pendidikan secara umum, lahirnya pendidikan sekular yang pragmatis dan ekonomis tentunya mempengaruhi pada perilaku anak didik tersebut. Sehingga timbul perilaku-perilaku tak terdidik, jauh dari sopan santun, tidak mencerminkan siswa yang berpendidikan. Terjadinya aksi tawuran yang kian hari semakin menjadi budaya dikalangan pelajar. Munculnya pelajar-pelajar yang terlibat aksi anarkis dan kriminal di mediamedia masa adalah bukan berita baru lagi. Lalu akan dibawa kemana dan dibentuk seperti apa wajah pendidikan ini jika siswa-siswanya kerap menjadi sasaran berita hangat di masyarakat dan media karena ulah dan perilaku yang tak beradab dan jauh dari cerminan akbläqulkarimah.

Lickona (2013, hlm. 20-30) memberikan sinyal kewaspadaan suatu bangsa sedang menuju jurang kehancuran. Tanda-tanda yang dimaksud adalah: (1) meningkatnya kekerasan dan perusakan dikalangan remaja, (2) semakin kaburnya pedoman moral baik dan buruk, (3) membudayanya ketidakjujuran, (4) semakin rendahnya rasa hormat kepada orang tua dan guru, (5) pengaruh peer grup yang kuat dalam tindak kekerasan, (6) adanya rasa saling curiga dan kebencian diantara sesama, (7) penggunaan kata dan bahasa yang memburuk, (8) meningkatnya perilaku merusak diri, seperti penggunaan narkoba, alkohol, dan seks bebas, (9) rendahnya rasa tanggung jawab individu dan warga negara, dan (10) menurunnya etos kerja.

Mochtar Buchori (dalam Muhaimin, 2004, hlm. 88) mengemukakan bahwa kegagalan pendidikan agama yang disebabkan karena praktik pendidikannya hanya memperhatikan aspek kognitif semata dari pertumbuhan kesadaran nilai-nilai (agama), dan mengabaikan pembinaan aspek afektif dan konatif-volutif yakni kemauan dan tekad untuk mengamalkan nila-nilai ajaran agama.

Akibatnya terjadi kesenjangan antara pengetahuan dan pengalaman antara gnosis dan praxis dalam kehidupan nilai agama. Atau dalam praktik pendidikan agama berubah menjadi pengajaran agama, sehingga tidak mampu membentuk pribadipribadi Islami. Terlebih lagi praktik pendidikan agama Islam di sekolah (umum) amatlah minim atau kurang maksimal. Secara umum, jumlah jam pelajaran agama di sekolah rata-rata 2 jam per minggu (Rouf, 2015, hlm. 187). Dengan alokasi waktu seperti itu, jelas tidak mungkin untuk membekali peserta didik dengan pengetahuan, keterampilan, serta pembinaan karakter yang baik.

Akhir akhir ini pemerintah mewacanakan tentang konsep pendidikan full day school. Menteri Pendidikan dan Kebudayaan Muhadjir Effendy yang mengatakan wacana sekolah seharian penuh (full day school). Disamping itu masyarakat muslim juga ramai membicarakan model Islamic full day school (Asyafah, 2016, hlm. 39) yang sesungguhnya banyak lembaga yang sudah melaksanakannya. Dalam berita 
online beliau mengatakan bahwa FDS tetap berjalan meskipun mendapat penolakan. "Full day (sehari penuh), jalan. Teknisnya belum, tetapi insya Allāh jalan. Itu berkaitan dengan pendidikan karakter tingkat SMP dan SMP," (Nurdiansyah, 2016, hlm. 1). Kemudian beliau menjelaskan lagi bahwa "full day school" bukan berarti belajar sehari penuh tetapi memastikan peserta didik mengikuti penanaman pendidikan karakter (Indriani, 2016, hlm. 1). Selanjutnya "bila penambahan jam belajar tersebut bisa berjalan dengan baik. Ketika Indonesia menginjak usianya ke-100, generasi mudanya sudah memiliki kepribadian yang baik, mampu berkompetisi, dan tidak cengeng. "Tidak gampang nangisan, tidak lembek. Justru memiliki kompetensi yang baik,". (Aminnudin, 2016, hlm. 1). Dengan adanya sistem FDS kiranya dalam pembelajaran PAI tidak hanya transfer of knowledge saja akan tetapai transfer of value dan transfer of culture bisa dilaksanakan dengan baik.

SMP Salman Al Farisi sebagai sekolah yang mengembangkan sistem full day school menjadi salah satu pilihan sekolah masa kini. Rentang waktu yang panjang di sekolah memungkinkan pengembangan potensi dan akhlak siswa yang lebih terpadu. Pengembangan ilmu pengetahuan, keterampilan dan sikap siswa dibangun melalui programprogram yang terintegrasi dalam membentuk karakter siswa berakhlak mulia, calon pemimpin masa depan melalui leadership life skill dan bertanggungjawab terhadap lingkungan melalui green education.
Pemanfaatan teknologi informasi dan komunikasi diarahkan kepada keterampilan siswa dan guru dalam mengembangkan media dan sumber belajar.

\section{Pengelolaan}

Pengelolaan merupakan terjemahan dari kata "management". Terbawa oleh penambahan kata kedalam Bahasa Indonesia, istilah Inggris tersebut lalu di menjadi "Pengelolaan" atau "menejemen". Menurut Winarno (2007, hal. 1), pengelolaan adalah substansi dari mengelola. Sedangkan mengelola berarti suatu tindakan yang dimulai dari penyusunan data, merencanakan, mengorganisasikan,melaksanakan

sampai dengan pengawasan dan penilaian. Pengelolaan diartikan sebagai suatu rangkaian pekerjaan atau usaha yang dilakukan oleh sekelompok orang untuk melakukan serangkaian kerja dalam mencapai tujuan tertentu.

Pengelolaanpembelajaran

merupakan proses untuk mencapa tujuan pembelajaran. Untuk mencapai tujuan pembelajaran diperlukan proses panjang yang dimulai dengan perencanaan, pengorganisasian dan penilaian. Perencanaan meliputi kegiatan menetapkan apa yang ingin dicapai, bagaimana mencapai, waktu dan dan personel yang diperlukan.

Sedang pengorganisasian merupakan pembagian tugas kepada personel yang terlibat dalam usaha mencapai tujuan pembelajaran, pengkoordinasian, pengarahan dan pemantauan. Evaluasi sebagai proses dilaksanakan untuk mengetahui ketercapaian tujuan yang telah

TARBAWY: Indonesian Journal of Islamic Education - Vol. 4 No. 2 (2017) | 181 
dicanangkan, faktor pendukung dan penghambatnya. Pengelolaan adalah proses mengatur agar seluruh potensi secara optimal dalam mendukung tercapainya tujuan yaitu perencanaan (planning), pengorganisasian (organizing), pengerahan (aktuating), pengawasan (controlling) (Zainy, 2016, hal. 37).

\section{Konsep Pendidikan Islam}

Berkenaan dengan tujuan pendidikan Islam An-Nahlawi (1996, hal.162) mengemukakan bahwa tujuan akhir pendidikan Islam adalah "merealisasikan ubudiyya kepada Allāh di dalam kehidupan manusia, baik individu maupun masyarakat". Selanjutnya Tujuan umum dari pendidikan Islam adalah " Muslim yang sempurna, atau manusia yang taqwa, atau manusia beriman, atau manusia yang beribadah kepada Allāh". Kemudian beliau lebih lanjut menjelaskan muslim yang sempurna mempunyai sembilan ciri sebagai berikut: sehat, kuat, berketerampilan, mampu menyelesaikan masalah secara cepat, tepat, ilmiah, dan filosofis, memiliki dan mengembangkan/sains dan filsafat. Selanjutnya hati yang takwa kepada Allāh dengan sukarela melaksanakan perintah Allāh dan menjauhi larangan-Nya, serta hati yang berkemampuan berhubungan dengan alam gaib (Tafsir, 2008, hal. 51).

Kemudian menurut Sayyed Naquib al-Attas (dalam Syahidin, 2009, hal.15) merumuskan tujuan pendidikan Islam adalah 'menghasilkan manusia yang baik'. Yang dimaksud manusia yang baik dalam kontek pendidikan Islam adalah manusia yang beradab, yakni manusia yang dapat menampilkan keutuhan antara jiwa dan raga dalam kehidupannya, sehingga ia selalu tampil berkualitas dan beradab.

Menurut Marimba (1962, hal. 44-46) suatu tujuan yang hendak dicapai oleh pendidikan pada hakikatnya adalah suatu perwujudan nilai-nilai ideal itu mempengaruhi dan mewarnai pola kepribadianmanusia, sehingga menimbulkan gejala dalam perilaku lahiriahnya. Dengan kata lain perilaku lahiriah adalah cerminan yang memproyeksikan nilai-nilai ideal yang telah mengacu di dalam jiwa manusia sebagai produk dari proses kependidikan.

\section{Perencanaan Pembelajaran}

Dimensi

perencanaan

pengajaran merupakan cakupan dan sifat-sifat $\geqslant$ yang ditemukan padaperencanaan pembelajaran. Pertimbangan terhadap dimensidimensi itu menurut Harjanto (Majid, 2011, hal.18) memungkinkan diadakannya perencanaan komperhensif yang menalar dan efisien. Dimensi tersebut adalah; 1) Signifikansi, yaitu tingkat signifikansi tergantung kepada tujuan pendidikan yang diajukan dan signifikansi dapat ditentukan berdasarkan kriteria-kriteria yang dibangun selama proses perencanaan. 2) Fasibilitas, maksudnya perencanaan harus disusun berdasarkan pertimbangan realistis baik yang berkaitan dengan biaya maupun pengelolaannya. 3) Relevansi, konsep relevansi berkaitan dengan jaminan bahwa perencanaan memungkinkan penyelesaian persoalan secara lebih spesifik pada waktu yang tepat agar dapat dicapai tujuan spesifik secara optimal. 4) Kepastian, konsep 
kepastian minimum diharapkan dapat mengurangi kejadian-kejadian yang tidak terduga. 5) Ketelitian.

\section{Pelaksanaan Pembelajaran}

Permendikbud Nomor 22

Tahun 2016 tentang standar proses pendidikan Dasar dan Menengah menjelaskan tentang tahapantahapanpelaksanaan pembelajaran yang merupakan Pengelolaan dari RPP, meliputi kegiatan pendahuluan, inti dan penutup.

Dalam kegiatan pendahuluan, guru wajib: menyiapkan peserta didik secara psikis dan fisik untuk mengikuti proses pembelajaran; 1) memberi motivasi belajar peserta didik secara kontekstual sesuai manfaat dan aplikasi materi ajar dalam kehidupan sehari-hari, dengan memberikan contoh dan perbandingan lokal, nasional dan internasional, serta disesuaikan dengan karakteristik dan jenjang peserta didik; 2) mengajukan pertanyaan-pertanyaan yang mengaitkan pengetahuan sebelumnya dengan materi yang akan dipelajari; 3) menjelaskan tujuan pembelajaran atau kompetensi dasar yang akan dicapai; dan 4) menyampaikan cakupan materi dan penjelasan uraian kegiatan sesuai silabus.

Kegiatan inti menggunakan model pembelajaran, metode pembelajaran, media pembelajaran, dan sumber belajar yang disesuaikan dengan karakteristik peserta didik dan mata pelajaran. Pemilihan pendekatan tematik dan /atau tematik terpadu dan/atau saintifik dan/atau inkuiri dan penyingkapan (discovery) dan/atau pembelajaran yang menghasilkan karya berbasis pemecahan masalah (project based learning) disesuaikan dengan karakteristik kompetensi dan jenjang pendidikan. Sikap sesuai dengan karakteristik sikap, maka salah satu alternatif yang dipilih adalah proses afeksi mulai dari menerima, menjalankan, menghargai, menghayati, hingga mengamalkan. Seluruh aktivitas pembelajaran berorientasi pada tahapan kompetensi yang mendorong peserta didik untuk melakuan aktivitas tersebut.

Pengetahuan dimiliki melalui aktivitas mengetahui, memahami, menerapkan, menganalisis, mengevaluasi, hingga mencipta. Karakteritik aktivititas belajar dalam domain pengetahuan ini memiliki perbedaan dan kesamaan dengan aktivitas belajar dalam domain keterampilan. Untuk memperkuat pendekatan saintifik, tematik terpadu, dan tematik sangat disarankan untuk menerapkan belajar berbasis penelitian (discovery/inquiry learning). Untuk mendorong peserta didik menghasilkan karya kreatif dan kontekstual, baik individual maupun kelompok, disarankan yang menghasilkan karya berbasis pemecahan masalah (project based learning).

Keterampilan diperoleh melalui kegiatan mengamati, menanya, mencoba, menalar, menyaji, dan mencipta. Seluruh isi materi (topik dan sub topik) mata pelajaran yang diturunkan dari keterampilan harus mendorong peserta didik untuk melakukan proses pengamatan hingga penciptaan. Untuk mewujudkan keterampilan tersebut perlu melakukan 
pembelajaran yang menerapkan modus belajar berbasis penyingkapan/penelitian

(discovery/inquiry learning) dan pembelajaran yang menghasilkan karya berbasis pemecahan masalah (project based learning).

Dalam kegiatan penutup, guru bersama peserta didik baik secara individual maupun kelompok melakukan refleksi untuk mengevaluasi seluruh rangkaian aktivitas pembelajaran dan hasil-hasil yang diperoleh untuk selanjutnya secara bersama menemukan manfaat langsung maupun tidak langsung dari hasil pembelajaran yang telah berlangsung. Selanjutnya memberikan umpan balik terhadap proses dan hasil pembelajaran. Terakhir melakukan kegiatan tindak lanjut dalam bentuk pemberian tugas, baik tugas individual maupun kelompok, dan menginformasikan rencana kegiatan pembelajaran untuk pertemuan berikutnya.

\section{Evaluasi Pembelajaran}

Dalam lampiran Peraturan Menteri Pendidikan dan Kebudayaan Nomor 22 Tahun 2016 Tentang Standar Proses Pendidikan Dasar dan Menengah telah dijelaskan penilaian proses pembelajaran menggunakan pendekatan penilaian otentik (authentic assesment) yang menilai kesiapan peserta didik, proses, dan hasil belajar secara utuh. Keterpaduan penilaian ketiga komponen tersebut akan menggambarkan kapasitas, gaya, dan perolehan belajar peserta didik yang mampu menghasilkan dampak instruksional (instructional effect) pada aspek pengetahuan dan dampak pengiring (nurturant effect) pada aspek sikap. Hasil penilaian otentik digunakan guru untuk merencanakan program perbaikan (remedial) pembelajaran, pengayaan (enrichment), atau pelayanan konseling. Selain itu, hasil penilaian otentik digunakan sebagai bahan untuk memperbaiki proses pembelajaran sesuai dengan Standar Penilaian Pendidikan. Evaluasi proses pembelajaran dilakukan saat proses pembelajaran dengan menggunakan alat: lembar pengamatan, angket sebaya, rekaman, catatan anekdot, dan refleksi. Evaluasi hasil pembelajaran dilakukan saat proses pembelajaran dan di akhir satuan pelajaran dengan menggunakan metode dan alat: tes lisan/perbuatan, dan tes tulis. Hasil evaluasi akhir diperoleh dari gabungan evaluasi proses dan evaluasi hasil pembelajaran.

\section{Konsep Full Day School}

Adapun istilah full day school merupakan saduran dari B. Inggris di mana Full artinya penuh, (Echlos, 1996, hal. 259) day artinya hari (Echlos, 1996, hal. 165) dan school artinya sekolah (Echlos, 1996, hal. 504). Jadi secara terminologi full day school artinya belajar sehari penuh. Sistem full day school juga mempunyai pengertian waktu pembelajaran hingga sore hari. Yang pada intinya konsep full-day school ini dalam pengertian yang sebenarnya, ditandai oleh waktu belajar yang lebih lama daripada sekolah-sekolah konvensional serta interaksi antara peserta didik dan pengaruh gurunya lebih intensif (Hawi, 2015, hal. 76)

Full day school sendiri merupakan satu istilah dari proses pembelajaran yang dilaksanakan secara penuh,

TARBAWY: Indonesian Journal of Islamic Education - Vol. 4 No. 2 (2017) | 184 
dimana aktifitas anak lebih banyak dilakukan di sekolah dari pada di rumah. Meskipun begitu, proses pembelajaran yang lebih lama di sekolah tidak hanya berlangsung di dalam kelas, karena konsep awal dibentuknya program full day school ini bukan menambah materi ajar dan jam pelajaran yang sudah ditetapkan oleh Depdiknas seperti yang ada dalam kurikulum tersebut, melainkan tambahan jam sekolah digunakan untuk pengayaan materi ajar yang disampaikan dengan metode pembelajaran yang kreatif dan menyenangkan untuk menambah wawasan dan memperdalam ilmu pengetahuan, menyelesaikan tugas dengan bimbingan guru, pembinaan mental, jiwa dan moral anak. Dengan kata lain konsep dasar dari full day school ini adalah integrated curriculum dan integrated activity (Romli, 2004, hal. 13).

Adapun garis-garis besar program full day school adalah sebagai berikut: Pertama, membentuk sikap yang Islami meliputi: Pengetahuan dasar tentang Iman, Islam dan Ihsan, Pengetahuan dasar tentang akhlak terpuji dan tercela, Kecintaan kepada Alloh dan Rosulnya, Kebanggaan kepada Islam dan semangat memperjuangkan. Kedua pembiasaan berbudaya Islam meliputi: Gemar beribadah, Gemar belajar, Disiplin, Kreatif, Mandiri, Hidup bersih dan sehat, Adab-adab Islam. Ketiga, Penguasaan Pengetahuan dan Ketrampilan meliputi: Pengetahuan materi-materi pokok program pendidikan, mengetahui dan terampil dalam beribadah sehari-hari, mengetahui dan terampil baca dan tulis al-Qur'ān, memahami secara sederhana isi kandungan amaliyah sehari-hari (Hawi, 2015, hal. 15).

Karakteristik yang paling mendasar dalam model pembelajaran Full day school yaitu proses Integrated curriculum dan integrated activity yang merupakan bentuk pembelajaran yang diharapkan dapat membentuk anak (siswa) yang berintelektual tinggi yang dapat memadukan aspek keterampilan dan pengetahuan dengan sikap yang baik dan Islami. Sekolah yang menerapkan pembelajaran full day school, dalam melaksanakan pembelajarannya bervariasi, baik ditinjau dari segi waktu yang dijadwalkan maupun kurikulum lembaga atau lokal yang digunakan, pada prinsipnya tetap mengacu pada penanaman nilai-nilai agama dan akhlak yang mulia sebagai bekal kehiduapan mendatang disamping tetap pada tujuan lembaga berupa pendidikan yang berkualitas (Romli, 2004, hal. 18).

\section{METODE PENELITIAN}

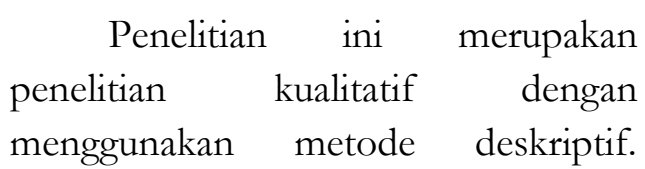
Penelitian ini dilakukan di SMP Islamic Full Day School Salman Al-Farisi Bandung yang beralamat di Jl. Tubagus Ismail VIII, Coblong Kota Bandung. Alasan peneliti memilih SMP Salman Al-Farisi sebagai lokasi penelitian adalah sebagai berikut; Pertama, SMP Salman Al-Farisi merupakan salah satu SMP yang keberadaannya sudah relatif lama, memiliki banyak peminat karena di samping letaknya sangat strategis ada di Bandung Utara yang telah memiliki

TARBAWY: Indonesian Journal of Islamic Education - Vol. 4 No. 2 (2017) | 185 
banyak alumni di Kota Bandung. SMP Salman Al-Farisi adalah salah satu SMP Swasta di Kota Bandung yang menerapkan sistem full day school, seperti telah diketahui bersama bahwa kebanyakan ciri masyarakat modern yang hidup di lingkungan perkotaan cenderung sehari-harinya sibuk bekerja (khususnya para orang tua, ayah dan ibu karir). Mereka mengharapkan pendidikan yang unggul dalam berbagai aspek, lembaga pendidikan yang mampu menggantikan tanggung jawab orang tua tatkala sibuk bekerja, dan mampu memberikan dasar-dasar kepribadian Islami, serta mampu bersaing dalam seleksi masuk SMA/MA/SMK unggulan di tengah persaingan yang ketat. Yayasan Pendidikan Salman Al-Farisi menciptakan lingkungan yang bisa menunjukkan, pada anak tentang nilainilai yang baik dan benar. Karena yang baik belum tentu benar, dan yang benar belum tentu baik. Di lingkungan Yayasan Pendidikan Salman Al Farisi anak-anak bebas berekspresi, bebas mengeluarkan pendapat dengan tanpa melanggar norma yang sudah ada. Anak-anak dilingkungan Yayasan Pendidikan Salman Al-Farisi dididik untuk berani tampil beda dengan gaya yang tetap sopan dan ucapan-ucapan yang santun. Berdasarkan uraian di atas peneliti memilih lokasi penelitian di SMP Salman Al-Farisi Kota Bandung. Karakteristik yang dimiliki SMP Salman Al Farisi, disarankan sesuai dengan kebutuhan peneliti tentang pengelolaan pendidikan agama Islam di Islamic full day school.

Hasil penelitian yang diperoleh melalui teknik observasi, wawancara dan studi dokumentasi, kemudian dianalisis dengan menggunakan konsep dari Miles dan Huberman yang terdiri dari teknik reduksi data reduction), penyajian data (data display), dan penarikan kesimpulan atau verifikasi (conclusion drawing verification). Setelah dianalisis, data yang diperoleh diperiksa keabsahannya dengan cara perpanjangan pengamatan, triangulasi dan menggunakan bahan referensi.

\section{HASIL PENELITIAN DAN PEMBAHASAN}

Perencanaan pendidikan agama Islam di SMP Salman Al-Farisi terbagi menjadi dua yang pertama perencanaan yang dibuat oleh yayasan, dan kedua perencanaan yang dibuat oleh guru. Perencanaan yang dibuat oleh yayasan melibatkan kepala sekolah, wakasek kurikulum, sebagian guru, dan bagian pendidikan yayasan salman al-Farisi. Perencanaan ini dibuat dalam forum lokal karya SMP Salman Al-Farisi yang dilaksanakan setiap semester satu minggu sebelum awal masuk tahun pelajaran. Adapun untuk pengawasan rapat dilakukan minggu kedua disetiap bulannya. Tugas tim ini adalah merumuskan konsep-konsep dasar, landasanlandasan, kebijaksanaan dan strategi utama dalam pengembangan kurikulum. Hal yang lainnya seperti merumuskan tujuan-tujuan yang lebih operasional, memilih materi, memilih strategi pembelajaran dan evaluasi, serta menyusun pedoman-pedoman pelaksanaan kurikulum bagi guru-guru. Setelah tim kerja selesai melaksanakan tugasnya, hasilnya dikaji ulang oleh tim pengarah serta para ahli lain yang

TARBAWY: Indonesian Journal of Islamic Education - Vol. 4 No. 2 (2017) | 186 
berwenang atau pejabat yang kompeten. Perencanaan yang dilakukan seperti tilawati (belajar membaca dan menulis Al-Qur`ān dengan metode tilawati), tahfiz, matrikulasi, jam walikelas, dan pembiasaan seven sunnah. Karena datangnya dari pihak yayasan, maka perencanaan pendidikan agama Islam ini termasuk kedalam model administrative atau Top - Down. Wina Sanjaya (2010, hal. 80) menjelaskan bahwa pengembangan kurikulum administrative muncul atas inisiatif para pejabat pendidikan atau para administrator atau dari para pemegang kebijakan (pejabat) pendidikan seperti dirjen atau para kepala Kantor Wilayah. Selanjutnya dengan menggunakan semacam garis komando, pengembangan kurikulum menetes kebawah.

Perencanaan selanjutnya yang membedakan dengan sekolah lain adalah pemetaan $\mathrm{KD} / \mathrm{SK}$ kedalam aspek leadership adapun pilar utama dari aspek leadership adalah mengenal diri, akhlak, komunikasi, proses belajar, mengatur, mengambil keputusan, dan kerja kelompok. Mengenal diri adalah mengenak sikap diri positif seperti bakat, potensi, minat, kemampuan, tingkat intelektual, emosi, gaya belajar, latar belakang budaya dsb.

Sedangkan metode dan media pembelajaran di SMP Salman Al-Farisi adalah dengan menggunakan konsep green education adapun yang menjadi pilarnya adalah mengenal alam, tumbuhan dan hewan, masalah lingkungan membangun komunitas, kesadaran global dan keterampilan hidup.
Dalam pelaksanaan pembelajaran seorang guru paling tidak harus melakukan dua pendekatan antara lain: pertama, pendekatan tidak disengaja. Pendekatan ini dilakukan tidak disengaja olenh pendidik karena terjadi di interaksi harian misalnya dalam proses belajar mengajar maupun pergaulan di luar kelas. Keberhasilan tipe keteladanan seperti keilmuan, kepemimpinan keikhlasan, penampilan, tingkah laku, tutur kata dan sebagainya. Dalam kondisi seperti ini berlangsung tanpa disengaja. Ini berarti bahwa setiap orang yang diharapkan jadi teladan hendaknya memelihara tingkah lakunya, disadari kesadaran bahwa ia bertanggung jawab dihadapan Allah. Kedua pendekatan yang disengaja pendekatan ini dilakukan dengan cara melakukan penjelasan atau perintah agar diteladani. Seperti lazimnya seorang pendidik memerintah muridnya untuk membaca, mengerjakan tugas sekolah, tugas rumah atau seorang pendidik member penjelasan di papan tulis kemudian ditiru oleh peserta didiknya. Pendidikan ini dilakukan agar peserta didik terbiasa dan terlatihdalam kedisiplinan dan keuletan dalam mempelajari ilmu pengetahuan. Pendekatan ini adalah pendekatan yang sering dilakukan Nabi Muhammad SAW bersama dengan para sahabatnya (Kosasih, 2010, hal. 23-24).

Hasil dari pendidikan agama Islam di Islamic full day school SMP Salman al-Farisi sesuai dengan target yang direncanakan pada setiap programnya dan dicantumkan dalam sebuah laporan capaian kompetensi 
peserta didik. Untuk mata pelajaran PAI, ada dua laporan; yang pertama laporan mata pelajaran pendidikan agama Islam yang sesuai dengan kementrian pendidikan nasional yang terdiri dari komponen; kompetensi dasar yang telah dicapai berupa nilai dari tiga aspek yaitu pengetahuan, keterampilan dan sikap. Serta keterangan pencapaian kompetensi peserta didik berupa deskripsi sikap, pengetahuan, dan keterampilan. Kedua laporan khusus aplikasi pendidikan agama Islam. Laporan ini adalah capaian kompetensi dari pengembangan pendidikan agama Islam mulai dari tilawati, marikulasi tabfir, jam wali kelas, leadership dan green education. Hasil akhir dari pendidikan agama Islam di Islamic full day school SMP Salman Al-Farisi adalah benar aqidahnya, kharimah akhlaknya, Cerdas akalnya (Nilai Akademis UnggulTuntas mencapai KKM), Benar dan baik ibadahnya : Melaksanankan ibadah Wajib/Sunnah, Target hafalan Qur'ān, Hafalan Doa, Hafalan Hadits, BTAQ dengan baik dan benar dan Sehat jasadnya: memiliki life skill yang baik, memiliki jiwa kepemimpinan yang bertanggung jawab, peduli pada lingkungannya.

Dengan sistem full day school berimplikasi terhadap pengembangan materi PAI sebagaimana yang telah dijelaskan dalam pembentukan beberapa program. Adapun bentuk program tersebut yaitu tilawati, tah fir, matrikulasi, jam wali kelas, pembiasaan seven sunnah dan pengintegrasian dengan mata pelajaran lain. Sistem full day school lebih memungkinkan terwujudnya pendidikan utuh. Karena menyentuh kepada tiga bidang yakni kognitif, afektif dan psikomotorik. Karena melalui full day school tendensi ke arah penguatan pada sisi kognitif saja dapat lebih dihindarikan, dalam arti aspek afektif siswa dapat lebih diarahkan demikian juga pada aspek psikomotoriknya. Sistem full day school lebih memungkinkan terwujudnya intensifikasi dan efektivitas proses edukasi. Konsep leadership dan green education diintegrasikan kedalam semua mata pelajaran baik dari segi perencanaan pelaksanaan maupun evaluasi. Hal ini dilakukan untuk mencapai tujuan dari lembaga yaitu menumbuh kembangkan fitrah manusia sebagai khaliffat fi al ard yang rahmatan li alamin. (Fahrun, 2012, hal. 35). Keuntungan lain yang bisa didapat adalah pihak sekolah akan lebih mudah mengontrol dan mengarahkan siswanya ke tujuan yang ingin dicapai.

Guru yang latar belakang pendidikannya tidak selinier menjadikan kesulitan tersendiri ketika mengembangakan perencanaan, pelaksanaan, dan evaluasi pembelajaran. Sistem full day school memerlukan perhatian dan kesungguhan pengelolaan bagi pengelola, agar proses pembelajaran pada lembaga pendidikan yang berpola full day school berlangsung optimal, sangat dibutuhkan perhatian dan curahan pemikiran terlebih dari pengelolaannya, bahkan pengorbanan baik fisik, psikologis, material dan lainnya.

Fahrun (2012, 40) menjelaskan dampak negatif program full day school adalah anak didik akan kelelahan setiba di rumah, kemudian tidur, dan

TARBAWY: Indonesian Journal of Islamic Education - Vol. 4 No. 2 (2017) | 188 
malamnya pun mereka dituntut untuk belajar. Artinya, tidak efektifnya waktu di rumah untuk anak-anak dengan dilaksanakannya program full day di sekolah. Oleh sebab itu di sini dituntut kearifan para orang tua di rumah. Meskipun demikian program full day school dinilai lebih banyak manfaatnya, karenanya ia terus dipraktekkan.

\section{KESIMPULAN}

Berdasarkan hasil analisis data yang telah diuraikan diatas, maka dapat ditarik kesimpulan sebagai berikut.

Perencanaaan pendidikan Agama Islam di SMP Salman AlFarisidengan menambah program pendidikan Agama Islam yaitu Tilawati (program khusus baca al-Qurān dengan menggunakan metode tilawai), matrikulasi (hafalan doa' harian dan hadis pilihan), serta kompetensi dasar yang ada dipetakan kedalam aspek leadership dan green school.

Pelaksanaan pendidikan agama Islam di SMP Salman Al-Farisi selalu terintegrasi dengan konsep leadership yaitu mengenal diri, komunikasi,akhlak,proses belajar, mengatur,mengambil, keputusan, dan kerja kelompok. Serta konsep green education yang mempunyai enam pilar yaitu mengenal alam, tumbuhan dan hewan, masalah-masalah lingkungan, membangun komunitas, kesadaran global, dan keterampilan hidup.

Hasil pendidikan agama Islam terdiri dari dua laporan capaian kompetensi peserta didik. Pertama laporan yang sesuai dengan kementrian pendidikan dan kebudayaan. Kedua laporan khusus pendidikan agama Islam yang dikembangkan oleh kurikulum yayasan.

Keunggulan pengelolaan pendidikan agama Islam di Islamic Full Day School SMP Salman Al-Farisi Bandung adalah mampu mengembangkan program pendidikan agama Islam dan mengintegrasikan leadership dan green education sebagai khalifat fi al ard yang rahmatan li älamin. Kelemahan latar belakang pendidikan guru yang masih belum sesuai dengan profesi yang diampu.

\section{REFERENSI}

Aminnudin, M. (2016, September 2). Most Popular: Detik News. Retrieved Desember 13, 2016, from Detik News: http://news.detik.com/berita/3 289746/mendikbud-sebutwacana-full-day-school-tetapjalan-ini-rencananya

Asyafah, A. (2016). Model Islamic Full Day School. Islamic Education Faces Global Challenges (pp. 39-48). Bandung: Alqaprint Jatinangor (Anggota Ikapi).

Echlos, J. (1996). Kamus Inggris Indonesia. Jakarta: Gramedia.

Fahrun. (2012). Kajian Fenomenologis Tentang Pola Pendidikan Karakter Melalui Sistem Full Day School Pada SMA Labschool Universitas Syah Kuala. Disertasi. Bandung: UPI.

Hawi, A. (2015). Sistem Full Day School di Sekolah Dasar Islam Terpadu (SDIT) Studi Kasus di 
Izzuddin Palembang. Jurnal Istinbath , 71-87.

Indriani. (2016, Agustus 9). Pendidikan: Antara News. Retrieved Desember 13, 2016, from Antara News: http:/ /www.antaranews.com/be rita/577611/mendikbudjelaskan-wacana-full-day-school

Kosasih, A. (2010, November 6). Universitas Pendidikan Indonesia. Retrieved oktober 3, 2017, from Universitas Pendidikan Indonesia: http://103.23.244.11/Direktori /FPIPS/M_K_D_U/19650917 1990011

ACENG_KOSASIH/Konsep_ Pend._Nilai.pdf

Lickona, T. (2013). Educating for Character: How our schools Can Teach Respect and Responsibility Trj. Juma Abdu Wamanno. Jakarta: Bumi Aksara.
Nurdiansyah, H. (2016, Agustus 11). Pendidikan Tempo.Co. Retrieved Desember 13, 2016, from Tempo.Co: https://m.tempo.co/read/news /2016/08/11/079794948/mend ikbud-wacana-full-day-schooltetap-jalan

Romli, M. (2004). Manajemen Pembelajaran di Sekolah Dasar Full Day School. Disertasi UM Malang. Malang: Universitas Muhammadiyah Malang.

Rouf, A. (2015). Potret Pendidikan Agama Islam di Sekolah Umum. Jurnal Pendidikan Agama Islam, 189-206.

Tafsir, A. (2008). Ilmu Pendidikan Dalam Perspektif Islam. Bandung: Remaja Rosdakarya.

Zainy, F. A. (2016). Pengelolaan Pembelajaran Mata Pelajaran Leadership. Bandung: Unisba.

TARBAWY: Indonesian Journal of Islamic Education - Vol. 4 No. 2 (2017) | 190 